\title{
ANNOUNCEMENT
}

\section{Fifth International Conference On Wind Engineering}

\section{Colorado State University, Fort Collins, Colorado, USA 80523 8-13 July 1979}

This Conference is organized to promote international communication of knowledge on wind engineering. Exchange of recent research findings by engineers, meteorologists and fluid dynamicists related to wind effects on buildings, structures, people, agriculture and energy production is a primary goal. An equally important objective is stimulation of interchange between research workers and practicing engineers, architects and planners.

Papers will be selected for presentation through review of complete paper manuscripts. Conference attendees upon registration will be provided with a preprint of papers to be presented. A Proceedings including discussions will be published after the Conference.

Topics For Papers: 1. Economic and Social Impact of Windstorms. 2. Characteristics of Boundary-layer Winds, Hurricanes, Tornadoes and Downslope Winds. 3. Wind Characteristics for Wind-power Installations. 4. Wind Loading of Buildings and Structures. 5. Wind-excited Motions of Buildings and Structures. 6. Local Wind Environment - Transport of Air Pollutants, Architectural and Agricultural Aerodynamics, Control Measures. 7. Physical Modeling in Wind Tunnels and Water Channels. 8. Full-scale Measurements. 9. Applications of Research Findings to Engineering Design.

For further information, write to:

Dr. J. E. Cermak, Fluid Mechanics and Wind Engineering Program, Department of Civil Engineering, Colorado State University, Fort Collins, Colorado, USA 80523 